\title{
Preoperative use of amoxicillin and gentamicin in elective orthopaedic surgery in horses - a randomised controlled study
}

\author{
Sabita D. Stöckle', Klaus Failing'ㄹ, Marc Koene ${ }^{3}$ and Kerstin Fey ${ }^{4}$ \\ Klinik für Pferde, Allgemeine Chirurgie und Radiologie, Freie Universität Berlin \\ ${ }^{2}$ AG Biomathematik und Datenverarbeitung, Fachbereich Veterinärmedizin, Justus-Liebig-Universität Gießen \\ 3 Tierklinik Lüsche, Bakum \\ ${ }^{4}$ Klinik für Pferde, Innere Medizin, Klinikum Veterinärmedizin der Justus-Liebig-Universität Gießen
}

\begin{abstract}
Summary: This randomised controlled trial evaluates the necessity of preoperative antimicrobial prophylaxis in equine clean, elective orthopaedic surgery. 75 horses undergoing clean orthopaedic surgery were randomly assigned to either a treated or a control group. Treated horses received $10 \mathrm{mg} / \mathrm{kg}$ amoxicillin and $6.6 \mathrm{mg} / \mathrm{kg}$ gentamicin once 30 to 45 minutes prior to first incision. The horses remained in the clinic for at least six days. During the first three days after surgery, rectal body temperatures were measured twice and on day four and five once daily. Surgical incisions received score points for exudation, swelling, skin temperature, and dehiscence. A two-factorial ANOVA was used to test for statistically significant differences between groups and over time. For pairwise comparisons between groups or time points, Fisher's exact test and the (exact) Wilcoxon-Mann-Whitney-test were used. 59/75 horses (78.7\%) were included in statistical analysis. Significantly higher scores for swelling $(p=0.002)$, and skin temperature $(p=0.007)$ were observed in treated patients $(n=28)$, which caused the total score to be significantly higher in treated horses, too $(p=0.002)$. In both groups, body temperatures were significantly higher in the evening of the day of surgery $(p<0.0001)$. On the third day after surgery, temperatures in the morning were significantly higher than in the evening $(p=0.007)$. All other statistical comparisons revealed no significant differences. After the seven-day observation period, one control horse (day 8 postoperatively) and one horse (day 9 postoperatively) in the treated group, that was excluded from statistical analysis due to additional gentamicin administration directly after the operation, developed septic arthritis in the operated joint. Preoperatively administered amoxicillin in combination with gentamicin failed to reduce reactions at incision sites after elective surgical orthopaedic procedures. The routine administration of preoperative antimicrobial prophylaxis in clean, elective orthopaedic surgery in horses lacks scientific data to prove a beneficial effect. Antibiotic administration before or after these procedures should be based on an individual risk-benefit assessment.
\end{abstract}

Keywords: surgical site infections, preoperative amoxicillin and gentamicin, elective surgery

Citation: Stöckle S. D., Failing K., Koene M., Fey K. (2020) Preoperative amoxicillin and gentamicin in elective orthopaedic surgery in horses A randomised controlled study. Pferdeheilkunde 37, 34-41; DOI 10.21836/PEM20210105

Correspondence: Sabita Diana Stöckle, Klinik für Pferde, Allgemeine Chirurgie und Radiologie, Oertzenweg 19b, 14163 Berlin, sabita.d.stoeckle@fu-berlin.de

Submitted: July 28, 2020 | Accepted: August 22, 2020

\section{Introduction}

With antibiotic resistance as one of the main world-wide health concerns, the antibiotic use and resistance in veterinary medicine is subject to close public attention (Johns et al. 2012). In any species, antibiotics induce bacterial resistance to the administered agents, e.g. in the gastrointestinal flora (Gibbens 2013). Resistance develops not only due to new mutations, but also through selection of already unsusceptible bacteria (D’Costa et al. 2011 ).

Nosocomial infections are recognised as a widely spread problem in human as well as in equine clinics. According to a study of antibiotic prophylaxis in 72 German human hospitals, 3.5\% of all patients develop a hospital-acquired infection (Wacha et al. 2010). Approximately $15 \%$ of these are surgical site infections (Wacha et al. 2010). Additionally to antisepsis, which was introduced by Joseph Lister (Daeschlein et al. 2015), antimicrobial prophylaxis is used in order to decrease the number of surgical site infections (Wacha et al. 2010, Daeschlein et al. 2015). The proliferation of bacteria can be suppressed if antibiotics are administered before the tissue is contaminated (Burke 1961). To be effective, the tissue concentration of the antibiotic agent must exceed $90 \%$ of the minimum inhibitory concentration (Kujath et al. 2006). During surgery, the tissue drug levels need to remain effective, so that after two half-live times of the antibiotic used, a second dose needs to be given (Wacha et al. 2010). However, in human medicine it is suggested that in clean orthopaedic surgeries, that do not exceed three hours, a repletion dose is not necessary. Routine administration of prophylactic antimicrobial agents for arthroscopic surgeries is no longer indicated, except if implants remain in the body (Széll et al. 2006). In a recent study on humans undergoing lesser toe fusion surgery, even despite an implant, no significant difference in the development of wound infections between antibiotic-receiving (48/100) and control (52/100) patients were found (Mangwani et al. 2017).

Rates lower than $1 \%$ for the development of a septic arthritis after equine arthroscopy have been reported (Olds et al. 
2006, Borg and Carmalt 2013). Even though these overall low joint infection rates, prophylactic antimicrobials still are very often routinely administered before or after clean orthopaedic surgical procedures in equines, because consequences of joint infections are severe (Borg and Carmalt 2013). Impaired healing after clean orthopaedic surgery was reported to range from 8.1-39.1\%; depending on the definition of complicated wound healing (MacDonald et al. 1994, Stöckle et al. 2018). Nearly all equine studies reported so far have a retrospective design. As a typical problem of retrospective analysis, surgical wounds of antibiotically treated and untreated patients are not directly comparable, mainly due to different treatments.

\section{Material and methods}

A randomized controlled clinical study was planned with a total of 60 patients. Horses undergoing elective orthopaedic surgery were examined repeatedly within seven days. Study probands had to be clinically healthy except for the orthopaedic purpose of surgery. Patients were assigned to the treated or control group in the evening before surgery according to a randomization list.

Patients in the treated group received $10 \mathrm{mg} / \mathrm{kg}$ amoxicillin (Belamox ${ }^{\circledR}$, bela-pharm, Vechta, Germany) and $6.6 \mathrm{mg} /$ $\mathrm{kg}$ gentamicin (Genta $100 \mathrm{mg} / \mathrm{ml}$, CP-Pharma, Burgdorf, Germany) through an i.v. catheter. Between administration and the initial incision 30 to 45 minutes passed. Horses of the control group received an i.v. catheter in the same time span as the verum group, but did neither receive antibiotics nor placebo. Drop-out criteria were contraction of a disease not associated with the surgical procedure, e.g. respiratory tract infection or surgical colic. Also dropped out of the study were horses that were not followed up according to the planned examination schedule or had their antibiotic protocol changed by the responsible surgeon. Patients leaving the hospital after less than five days after surgery were also dropped out.

Rectal temperatures were obtained at day $0-3$ in the morning and evening and at days 4-5 just in the morning. Wounds were evaluated three times postoperatively with a semi-quantitative scoring system considering exudation, swelling, skin temperature and dehiscence; all score points were added to a total score (Table 1). Skin temperature was determined by palpation of the area surrounding the incision with the back of a gloved hand. In patients with more than one surgical intervention, the highest score reached in a lesion was included in the results.

Distal limb bandages consisted of a layer of mull (Vetrol Mullwatterolle, Farm and Stable KG, Wiehl/Germany) fixed with an elastic bandage (Raucolast ${ }^{\circledR}$, Lohmann-Rauscher, Neuwied/Germany) and then covered with a self-adhesive bandage (Prowrap, Farm and Stable KG, Wiehl/Germany). If the operated joint was the coffin joint, the bandage was fixed distally with adhesive tape to the hoof (Gewebe Reparaturband silber, engelbert strauss $\mathrm{GmbH}$, Biebergemünd/ Germany). After tarsus arthroscopies, bandages consisted of a layer of mull and an adhesive bandage (Optiplaste ${ }^{\circledR}-\mathrm{C}, \mathrm{BSN}$ medical GmbH, Hamburg/Germany). In pa- tients recovering from a knee surgery, a bandage was not applied. Instead the incision sites were covered with ESS Zinc Cover (ESS GmbH, Bakum/Germany). Surgical lesions at the knee were looked after daily but evaluation results just of the first, third and fifth day after surgery entered statistical analysis.

Horses not registered for food production received phenylbutazone $\left(2.5 \mathrm{mg} / \mathrm{kg}\right.$ b.i.d. orally; Phenylbutariem ${ }^{\circledR}$ Ecuphar NV/SA, Oostkamp/Belgium), whereas horses with the option to be slaughtered received meloxicam $10.6 \mathrm{mg} / \mathrm{kg}$ once a day orally; Metacam ${ }^{\circledR} 15 \mathrm{mg} / \mathrm{ml}$, Boehringer Vetmedica Ingelheim, Ingelheim, Germany). The medication started on the evening prior to surgery and ended in the morning on the fourth day after surgery.

For statistical analysis, the program package BMDP/Dynamic, Release 8.1 (Statistical Solutions Ltd., Cork, Ireland) was used to conduct different ANOVAs, the t-test, and the Wilcoxon-Mann-Whitney test (WMWT). The statistical program package StatXact-9 (9.0.0 Cytel, Cambrige, Massachusettes, USA) (15) was used additionally for Fisher's exact test, the exact WMWT, and the chi-square test.

Two-factorial ANOVAs were calculated to evaluate the influence of antimicrobial treatment and time (repeated measures) including the interaction between these factors on scores (in a manner of exploratory data analysis) and body temperatures (program BMDP2V). On day 1-3, horses' temperatures were taken twice a day, therefore a three-factorial ANOVA with repeated measures was performed to test for influences of daytime, day and perioperative antimicrobial prophylaxis including their interactions (BMDP2V). In cases with incomplete

\begin{tabular}{|c|c|c|}
\hline \multicolumn{3}{|c|}{$\begin{array}{l}\text { Table } 1 \quad \text { Wound scoring system } \\
\text { Score Punkten }\end{array}$} \\
\hline \multirow[t]{2}{*}{ Parameter } & & Score \\
\hline & None, wound is dry and clean & 0 \\
\hline \multirow{2}{*}{ Exudate } & Serous or serosanguinous & 1 \\
\hline & Purulent or haemopurulent & 3 \\
\hline \multirow{4}{*}{ Swelling and pain } & No swelling & 0 \\
\hline & Low-grade swelling, not painful & 1 \\
\hline & $\begin{array}{l}\text { Middle-grade swelling, mildly } \\
\text { painful }\end{array}$ & 2 \\
\hline & $\begin{array}{l}\text { High-grade swelling, severely } \\
\text { painful }\end{array}$ & 3 \\
\hline \multirow{4}{*}{ Extend of calor } & Normal skin temperature & 0 \\
\hline & Mild increase & 1 \\
\hline & Moderate increase & 2 \\
\hline & Severe increase & 3 \\
\hline \multirow{4}{*}{ Dehiscence } & No sutures dehiscent & 0 \\
\hline & 1-2 sutures dehiscent & 1 \\
\hline & $\begin{array}{l}\leq 50 \% \text { of sutures dehiscent if } \\
\text { more than } 2 \text { sutures were applied }\end{array}$ & 2 \\
\hline & $>50 \%$ of sutures dehiscent & 3 \\
\hline
\end{tabular}


data sets, the Wald test was applied (method of maximum likelihood, program BMDP5V).

The t-test was used to look at possible differences between the groups temperatures on the day prior to surgery, day four and day five after surgery. The WMWT respectively the exact WMWT (in case of several ties in the data) was applied to duration of surgery, exudation scores or scores for swelling and skin temperature as well as to the total score per clinical evaluation. Fisher's exact test was used to test the groups for differences in type of surgery, number of operated legs/ joints, number of patients receiving either phenylbutazone or meloxicam, the surgeon and the gender of the patient. Metric data are represented as mean \pm standard deviation (minimum - maximum), if not mentioned differently. For qualitative variables frequency tables were formed. The significance level was set as usual at 0.05 .

The aim of the study was the recognition of conspicuous differences between the treatment groups. Therefore no adjustment for multiple testing (correction of error probability of the first kind due to multiple testing) was done to avoid the reduction of statistical power.

\section{Ethical statement}

In comparison to the usual procedures in the clinic, no additional examinations or additional blood samples were taken, just the blood volume was increased to a total volume of $25-30 \mathrm{ml}$ per sample. According to the relevant authority (Regierungspräsidium Gießen), at that time, the animal welfare laws in Germany therefore did not require an approval procedure.

\section{Results}

\section{Drop outs}

In total, 75 horses needed to be included and randomised in order to reach a total of 28 antibiotically treated patients and 31 controls. Sixteen patients (21.3\%) dropped out of the study. Seven were randomised into the amoxicillin/gentamicin group ("treated"), nine were intended to be controls. Thirteen of the 16 drop-outs underwent arthroscopy. Tendovaginoscpy, fasciotomy, and fasciotomy/neurectomy were performed on one patient each. The reasons for drop-out were as follows: Three horses in the treatment group received additional antibiotics due to concerns of the surgeon. One patient (control) developed a severe respiratory infection and one horse (treated) had surgical implants placed. Six horses (1 treated, 5 controls) were discharged earlier than planned. Five more horses could not be examined as scheduled.

\section{Patient data}

Of the 59 horses fulfilling the study plan, 28 received preoperative amoxicillin/gentamicin and 31 served as controls. Fifty warmbloods (26 treated, 24 controls), three ponies, two Arabian horses, two Quarter Horses, one Frisian as well as one Icelandic horse were included (2 treated, 7 controls). Eleven were stallions (6 treated, 5 controls), 31 geldings (16 treated, 15 controls), and 17 mares (6 treated, 11 controls). Statistically, gender was distributed evenly between the groups $(p=0.57)$.

There were no significant differences between treated and control group in age $(5.3 \pm 2.8$ versus $5.3 \pm 1.9$ years), weight $(525.6 \pm 109.7$ versus $541.7 \pm 73.2 \mathrm{~kg})$, duration of the surgery $(60 \pm 23$ versus $55 \pm 19$ minutes) and hospitalisation time. The median ( $\min -\max$ ) hospitalization time of the control group was 11 (6-43) days, whereas patients in the treated group stayed 10 (5-77) days.

As NSAID, 44 horses received phenylbutazone and 15 meloxicam. Controls received statistically significantly $(p=0.03)$ more often phenylbutazone $(27 / 31 ; 87 \%)$ than patients in the treated group $(17 / 28 ; 61 \%)$.

\section{Types of surgical interventions}

Most study participants $(36 / 59 ; 61 \%)$ underwent arthroscopy (Table 2). Of these, 19 were controls and 17 received preoperative antimicrobial prophylaxis. For the different types of surgeries, there was no significant difference between the number of horses per groups.

Often simultaneously performed and therefore summarised in one group for statistical analysis were tendovaginoscopy and tenotomy. One horse underwent a tendovaginoscopy, tenotomy, and a splint bone extraction on the same leg. As the tendovaginoscopy/tenotomy took longer than the splint bone extraction, the horse was assorted to the tendovaginosyopy/ tenotomy group. Fasciotomy, neurectomy and their combination were summarized for statistical evaluation, because in the hind limbs these surgeries were mainly performed simultaneously.

Forty-six horses had one surgical intervention, 22 (48\%) of these received antibiotics. Eleven horses underwent two interventions during their surgery session, 5 of them were treated with antibiotics. Two horses (1 treated) had three arthroscopies during their one surgery session. Horses with one and patients with two or more surgical lesions were distributed evenly between treatment and control group.

Thirty surgeries (13 treated, 17 controls) were performed by surgeon $A$, and surgeon $B$ operated 21 horses $(10$ treated, 11 controls). Three more surgeons performed the remaining

\begin{tabular}{ccc}
\hline $\begin{array}{l}\text { Table } 2 \\
\text { Anzahl der Patienten pro Operation }\end{array}$ & $\begin{array}{c}\text { Patient distribution according to types of surgery } \\
\text { Treated }(\mathrm{n}=28)\end{array}$ & $\begin{array}{c}\text { Controls } \\
(\mathrm{n}=31)\end{array}$ \\
\hline Arthroscopy & $17(60.7 \%)$ & $19(61.3 \%)$ \\
\hline Tendovaginoscopy/Tenotomy & $5(17.9 \%)$ & $4(12.9 \%)$ \\
\hline Splint bone extraction & $2(7.1 \%)$ & $6(19.4 \%)$ \\
Neurectomy/Fasciotomy & $4(14.3 \%)$ & $2(6.5 \%)$ \\
\hline
\end{tabular}


8 procedures (5 treated, 3 controls). There was no significant difference in distribution of antimicrobial prophylaxis between the surgeons.

\section{Body temperatures}

It was not possible to take temperatures in 10 patients at all occasions because they were very uncooperative. In four horses, of which three were in the control group, temperature measurements never were possible. In a further six horses (5 control, 1 treated) only 23 out of the planned 66 measurements per horse could be taken.

Five horses (4 controls, 1 treated) showed body temperatures $>38.5^{\circ} \mathrm{C}$ at least once (Fig. 1). In the evening after surgery, two controls developed fever $\left(40.2^{\circ} \mathrm{C}\right.$ and $\left.39.1^{\circ} \mathrm{C}\right)$ and one treated horse a slightly elevated $\left(38.6^{\circ} \mathrm{C}\right)$ temperature.

Between groups, no statistically significant difference in mean body temperatures of day 1 to 3 was seen. However, between days temperatures were significantly different $(p=0.02)$ and a significant interaction of day and daytime was detected $(p<0.0001)$. On the day of surgery, body temperatures were significantly higher in the evening $\left(37.8+/-0.54{ }^{\circ} \mathrm{C}\right.$ than they had been in the morning $\left.37.4+/-0.48^{\circ} \mathrm{C} ; \mathrm{p}<0.0001\right)$. On the third day after surgery, temperatures in the morning (37.6 $\left.+/-0.48^{\circ} \mathrm{C}\right)$ statistically were significantly $(p=0.007)$ higher than in the evening $\left(37.4+/-0.42^{\circ} \mathrm{C}\right)$.

\section{Wound scores}

Over time, the total score decreased significantly during the five-day evaluation period ( $p<0.0001$, Table 3 ). Total scores were significantly higher in the treated group than in the control group $(p=0.002)$. Analysis on a daily basis (Wilcoxon-Mann-Whitney Test) revealed, that the total score in treated horses was significantly higher at day $1(p=0.03)$ and 5 $(p=0.01)$. On day 3 , the difference between the groups was not significant $(p=0.06)$.

However, in both groups, most horses only had an absolute total score of 3 points or less (figure 1 - figure 6). The highest scores (total score treated: 3,38 $\pm 1,54$; control: $1.48 \pm 1.12$ ) were observed in the treated group on day one.

Purulent wound discharge (3 score points) was only observed in one horse (horse 61) in the treated group on day 5. This patient underwent neurectomy. Like in the previous evaluations, the wound additionally showed a low-grade swelling (1 score point), no increase in skin temperature (0 score points), and no dehiscence. The patient responded well to local treatment. After the evaluation at day 5, the wound was cleaned daily, disinfected with octenidine (Octenisept ${ }^{\circledR}$, Schülke and Mayr GmbH, Norderstedt/Germany) and an antibiotic ointment was applied.

Dehiscence developed in three of the 59 patients. On the first day after surgery, sutures were not in situ in two patients of the
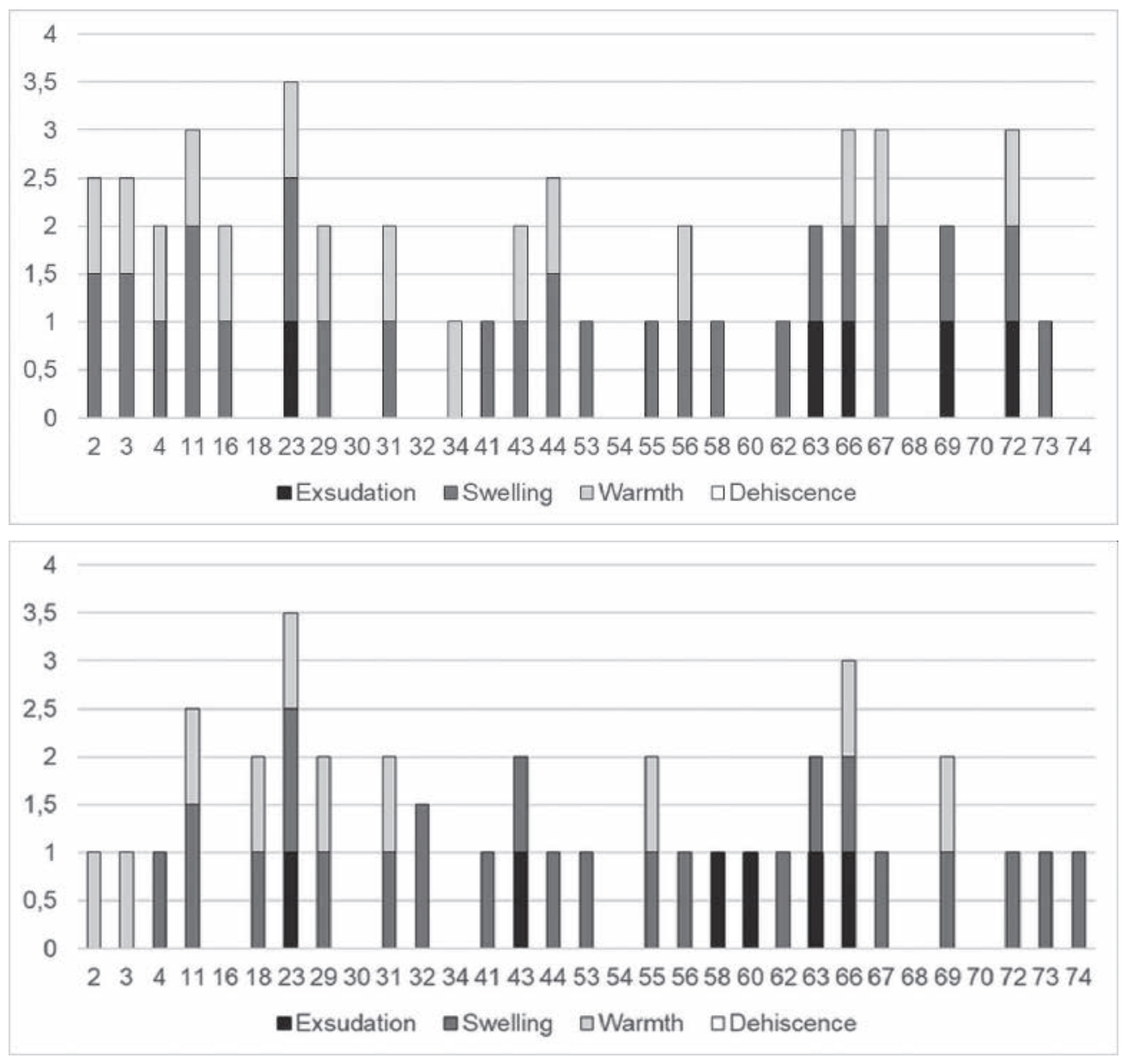

Fig. 1 Individual wound scores in controls on day 1. $x$-axis: horse number, y-axis: score points | Individuelle Wundscores der Kontrollgruppe an Tag 1. x-Achse: Pferdenummer, $y$-Achse: Score Punkte
Fig. 2 Individual wound scores in controls on day 3. $x$-axis: horse number, y-axis: score points | Individuelle Wundscores der Kontrollgruppe an Tag 3. x-Achse: Pferdenummer, $y$-Achse: Score Punkte 
antibiotically treated group. In horse 21 , none of the two sutures was in place at an arthroscopy portal. A splint bone was extracted in horse 64. Two skin sutures out of seven were dehiscent. On day five, one control (splint bone removal) the lowest two of seven sutures became dehiscent (1 point). All three patients responded to local treatment and were discharged sound.

During the first five days after surgery, the treated horses showed significantly more swelling at the incision site than horses in the control group $(p=0.002)$. The swelling decreased significantly during the observation period $(p<0.0001)$. Horses in the treated group had significantly higher swelling scores on the first $(p=0.02)$ and fifth $(p=0.002)$ day after surgery than controls. However, there was no significant difference between groups on the third day $(p=0.1)$. On the first day after surgery, the surgical wounds in eleven horses did not show any swelling at all (treated: 2; control: 9). On day one, the swelling around the incision in most horses (treated: 14; control: 16) was scored with one point. The highest score given on this day was 2 points, which was attributed to 6 horses in the treated and to 2 horses in the control group. Only one treated patient developed swelling scored with three points on the fifth day after surgery. Additional complications did not occur in this horse.

During the study period, treated horses had statistically significant higher skin temperatures around their incisions than the horses in the control group $(p=0.007)$. The skin temperature differed significantly over time $(p=0.0002)$. Regarding each time point individually, the skin temperature around the in-
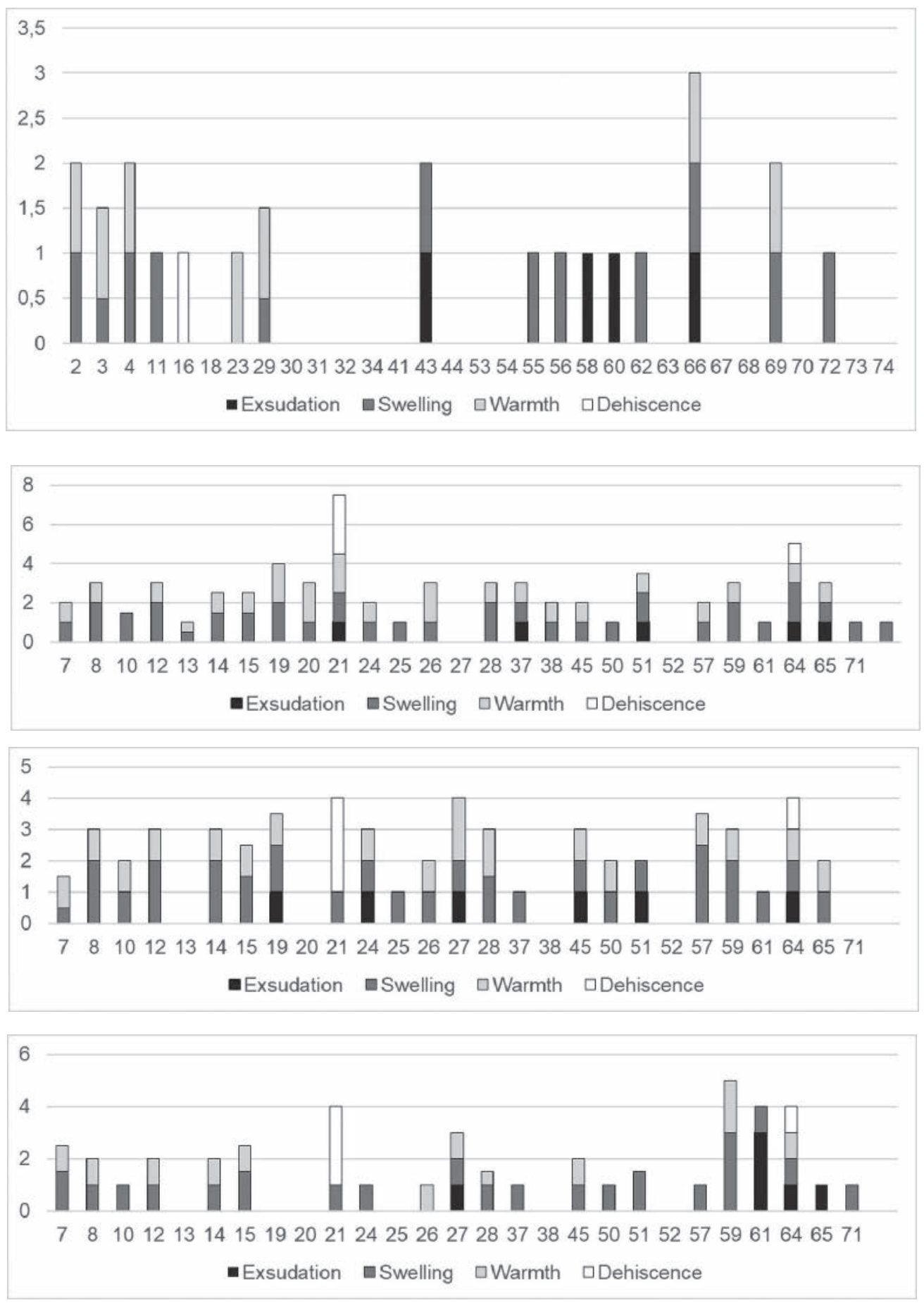

Fig. 3 Individual wound scores in controls on day 5. x-axis: horse number, y-axis: score points | Individuelle Wundscores der Kontrollgruppe an Tag 5. x-Achse: Pferdenummer, y-Achse: Score Punkte

Fig. 4 Individual wound scores in treated horses on day 1. x-axis: horse number, $y$-axis: score points | Individuelle Wundscores der behandelten Gruppe an Tag 1. x-Achse: Pferdenummer, $y$-Achse: Score Punkte

Fig. 5 Individual wound scores in treated horses on day 3. $x$-axis: horse number, $y$-axis: score points | Individuelle Wundscores der behandelten Gruppe an Tag 3. $x$-Achse: Pferdenummer, $y$-Achse: Score Punkte

Fig. 6 Individual wound scores in treated horses on day 5. x-axis: horse number, y-axis: score points | Individuelle Wundscores der behandelten Gruppe an Tag 5. $x$-Achse: Pferdenummer, $y$-Achse: Score Punkte 
cisions was significantly higher in horses that had received perioperative antimicrobials on the days $1(p=0.04)$ and 3 $(p=0.03)$ after surgery. To the incisions in the control group, 0 or just 1 point was given during the study period. Four horses in the treated group received 2 points on day one due to their skin temperature around the incision. On days 3 and 5, it was one treated horse that received 2 points on each day.

\section{Post-operative septic arthritis}

Septic arthritis developed in one (treated) drop-out and one control patient at day 8 and 9 post-operatively, after the end of the study. The treated horse already dropped out of the study due to additional gentamicin on day 1 and 2 after surgery.

\section{Discussion}

To the authors' knowledge, this is the first prospective, controlled clinical study on preoperative antimicrobial prophylaxis in elective, clean orthopaedic surgery in horses.

Due to the prospective study design, all probands were examined and treated at the same time points and received the antibiotics in the same dosages, which allows directly comparable wound evaluations. Additionally, a scoring system was established before the start of the study, therefore wound evalvations were possible in a standardised manner.

The total wound evaluation score was significantly higher in the treated than the control patients on days one and five. Randomly allocated, antibiotic-receiving horses showed significantly higher scores for local swelling and skin temperature on days one and three. On the other hand, overall and even initial wound scores were quite low with many patients showing uncomplicated healing with 0 score points at all times. Nevertheless, total as well as scores for swelling and elevated skin temperature decreased significantly over time, showing that the score system is sensitive enough to detect differences. A bias due to knowledge of the examiners concerning the group association of the patient, has to be considered. A systematic influence was avoided to the best of the authors knowledge by defining the criteria for score point assignment before the start of the study and by enhancing the awareness of a possible bias. A blinded study design would have been better but was not possible to realize.

Table 3 Wound scores: statistical results (two-factorial ANOVA with repeated measures; exploratory data analysis) | Statistische Ergebnisse der zweifaktoriellen ANOVA mit Messwiederholungen als explorative Datenanalyse für die Wundscores

\begin{tabular}{cccc}
\hline & $\begin{array}{c}\text { Difference } \\
\text { between groups }\end{array}$ & $\begin{array}{c}\text { Differences } \\
\text { between days }\end{array}$ & Interactions \\
\hline Total score & 0.002 & $<0.0001$ & n.s. \\
Exudation & n.s. & n.s. & n.s. \\
Swelling & 0.002 & $<0.0001$ & n. s. \\
Skin temperature & 0.007 & 0.0002 & n.s. \\
Dehiscence & n.s. & n.s. & n.s. \\
\hline
\end{tabular}

MacDonald et al. (1994) found a significantly higher risk of developing surgical site infections under antibiotic cover in their retrospective analysis. The authors assumed that this was caused by the identification of additional risk factors by the responsible surgeon. Despite the antibiotic cover, those high-risk patients remained to have an increased risk of complications - which probably would have been even higher if they had not received antibiotics. The study presented here allowed additional antibiotics, if the surgeon felt that they were needed. Three patients dropped out due to this reason. Due to randomization, the remaining horses in both groups should have the same risk of developing surgical site infections, especially since age, duration and types of surgery, hospitalisation time etc. were not different between groups. The results in body temperatures as well as wound scores underline, that the healing process in the control group was certainly not inferior in comparison to the group receiving "prophylactic" antibiotics.

In this study 47 arthroscopies were performed in 36 horses. One control developed a septic coffin joint on day 8 after surgery, after the end of the study observation period. With an antibiotic cover, none of the 22 joints in the 17 horses involved showed such a complication. However, one excluded horse, initially randomised into the treatment group, developed a septic coffin joint despite receiving the routine amoxicillin/gentamicin combination preoperatively and additional gentamicin for two days after the arthroscopy. This dropped-out horse emphasizes the importance of including a sufficient number of horses in order to produce valid recommendations. As the onset of the septic arthritis was 8 or 9 days after surgery, the observation period of five days was probably not long enough to cover this severe complication after arthroscopy, which is underlined by retrospective studies, in which in total 14 out of 1145 horses developed a septic joint after arthroscopy. (Olds et al. 2006, Borg and Carmalt 2013, Stöckle et al. 2018). In one study, septic joints occurred after 2-27 days after surgery (Stöckle et al. 2018), in the other after a median of 20 days (mean 47 days) after surgery (Olds et al. 2006). Horses in our study were continuously monitored either by the clinic or the owner/trainer, who with a very high probability would have contacted the clinic in any case of complications. Therefore, it is unlikely, that septic arthritis was missed in any of the patients reported here. Furthermore, surgical site infections are defined to occur within 30 days after the surgical procedure if no implant was placed and within a year when an implant remains in the body (Waguespack et al. 2006). It was already hypothesized that the contamination of operated joints can occur at some point after surgery (Smith et al. 1982). Therefore it seems very unlikely that preoperative application of antibiotics as a single shot will prevent any infections occurring at some point after surgery. It needs to be emphasized, that after arthroscopy, a joint may still develop an infection within the following weeks and then requires intensive therapy immediately. During the first five days after surgery, increased swelling or increased skin temperature occured, which can be indicative of developing septic arthritis or more superficial surgical site infections. Horses showing these signs were monitored closely even after finishing the study period. Furthermore, if there would have been any concern in the owner or the trainer about the healing of a discharged horse after surgery, due to overall intense contact with the clients, the clinic certainly would have been informed. Therefore, it seems very unlikely that any complications occurring after discharge were missed. 
Unfortunately, a significant difference between the treated and control group was detected regarding the NSAID applied. The treated horses received significantly more often meloxicam than the controls $(p=0.03)$. Forty-four horses did not receive meloxicam because of the higher costs. Fifteen horses were intended for human consumption, so an administration of phenylbutazone was not an option due to legal reasons. A recent study compared the efficacy of meloxicam and phenylbutazone in two experimental pain models in horses. In a lipopolysaccharide (LPS)-induced synovitis model, in which 16 horses received $50 \mathrm{ng}$ of LPS in $0.5 \mathrm{ml}$ Ringer's solution into one intercarpal joint, both meloxicam and phenylbutazone reduced the joint temperature compared to a placebo. The inflammatory pain was evaluated by scoring pawing the floor or pointing a foot, movement, position in the stall, ear position, and orbital tightening. Regarding lameness, there was no significant difference between meloxicam and phenylbutazone, but meloxicam was more effective than phenylbutazone in reducing synovitis-associated changes in head movement (Banse and Cribb 2017). In the study presented here, neither lameness after surgery nor pain on palpation were observed in any of the patients. As a systemic inflammatory response, fever was present in 3 horses that received meloxicam as well as in 2 patients receiving phenylbutazone. The total scores were highly variable after meloxicam as well as after phenylbutazone so that an influence of the NSAID on the score points in each group was not assumed. Furthermore, in three of the phenylbutazone-receiving horses, suspected adverse reactions were seen: two patients showed elevated creatinine levels, and one horse was anorectic. After discontinuing the NSAID on the day after surgery, the creatinine levels returned to normal limits, and the third horse started eating again. In these patients, excessive elevations of the inflammatory parameters were not observed, so an effect of the absent non-inflammatory medication on wound healing seems implausible. Therefore, it seems reasonable to critically evaluate the type and the duration of postoperative analgesia with NSAIDs.

\section{Conclusion}

Preoperative antimicrobial prophylaxis failed to reduce post-operative wound scores and should therefore not be initiated routinely in uncomplicated equine clean orthopaedic surgery.

\section{Conflict of interest}

The authors declare no conflict of interest.

\section{References}

Banse H., Cribb A. E. (2017) Comparative efficacy of oral meloxicam and phenylbutazone in 2 experimental pain models in the horse. Can. Vet. J. 58. 157-167
Borg H., Carmalt J. L. (2013) Postoperative septic arthritis after elective equine arthroscopy without antimicrobial prophylaxis. Vet. Surg. 42, 262-266; DOI 10.1111/i.1532-950X.2013.01106.x

Burke J. F. (1961) The effective period of preventive antibiotic action in experimental incisions and dermal lesions. Surgery 50, 161168

D'Costa V. M., King C. E., Kalan L., Morar M., Sung W. W., Schwarz C., Froese D., Zazula G., Calmels F., Debruyne R., Golding G. B., Poinar H. N., Wright G. D. (2011) Antibiotic resistance is ancient. Nature 477, 457-461; DOI 10.1038/nature 10388

Daeschlein G., Napp M., Layer F., von Podewils S., Haase H. , Spitzmueller R., Assadian O., Kasch R., Werner G., Jünger M., Hinz. P., Ekkernkamp A. (2015) Antimicrobial efficacy of preoperative skin antisepsis and clonal relationship to postantiseptic skin-andwound flora in patients undergoing clean orthopedic surgery. Europ. J. Clin. Microbiol. Infect. Dis. 34, 2265-2273; DOI 10.1007/ s10096-015-2478-7

Gibbens N. (2013) Exploring opportunities how to do things differently. Vet. Rec. 173, 179-181; DOI 10.1136/vr.f5217

Johns I., Verheyen K., Good L., Rycroft A. (2012) Antimicrobial resistance in faecal Escherichia coli isolates from horses treated with antimicrobials: A longitudinal study in hospitalised and non-hospitalised horses. Vet Microbiol 159 381-389; DOI 10.1016/i. vetmic.2012.04.010

Kujath P., Bouchard R., Scheele J., Esnaashari H. (2006) Neves in der perioperativen antibiotischen Prophylaxe. Chirurg 77, 490-498; DOI 10.1007/s00104-006-1194-3

MacDonald D. G., Morley P. S., Bailey J. V., Barber S. M., Fretz P. B. (1994) Anexamination of the occurrence of surgical wound infection following equine orthopaedic surgery (1981-1990). Equine Vet. J. 26, 323-326; DOI 10.1111/i.2042-3306.1994. tb04394.x

Mangwani J., Gulati A., Benson R., Cichero M., Williamson D. M. (2017) Role of prophylactic antibiotics in lesser toe fusion surgery: A prospective randomised controlled trial. Foot Ankle Surg. 23, 50-52; DOI 10.1016/j.fas.2016.02.004

Olds A. M., Stewart A. A., Freeman D. E., Schaeffer D. J. (2006) Evalvation of the rate of development of septic arthritis after elective arthroscopy in horses: 7 cases (1994-2003). J. Am. Vet. Med. Assoc. 229, 1949-1954; DOI 10.2460/javma.229.12.1949

Orsini J. A. (2017) Meta-analysis of clinical factors affecting synovial structure infections and prognosis. J. .Equine Vet. Sci. 55, 105-114

Smith R. L., Merchant T. C., Schurman D. J. (1982) In vitro cartilage degradation by Escherichia coli and Staphylococcus aureus. Arthritis Rheum. 25, 441-446

Stöckle S. D., Failing K., Koene M., Fey K. (2018) Postoperative complications in equine elective, clean orthopaedic surgery with/without antibiotic prophylaxis. Tierärztl. Prax. Ausg G 46, 81-86 DOI 10.15653/TPG-170491

Széll M., Hofmann S., Pietsch M., Gerhart E., Wenisch C. (2006) Perioperative antibiotische Prophylaxe. Orthopäde 35, 805-814; DOI 10.1007/s00132-006-0974-2

Wacha H., Hoyme U., Isenmann R., Kujath P., Lebert C., Naber K., Salzberger B. (2010) Empfehlungen einer Expertenkommission der Paul-Ehrlich-Gesellschaft für Chemotherapie e. V. 19, 70-84

Waguespack R. W., Burba D. J., Moore R. M. (2006) Surgical site infections and the use of antimicrobials. Equine Surgery. J. A. Auer, J. A. Stick. St. Louis, Missouri, USA, Elsevier 70-87. ISBN 13: 9781-4160-0123-2 